\title{
Mammography screening and mortality by risk status in the California teachers study
}

Hannah Lui Park ${ }^{1,2^{*}}$, Jenny Chang ${ }^{3}$, Vikram Haridass ${ }^{2}$, Sophia S. Wang ${ }^{4}$, Argyrios Ziogas ${ }^{3}$ and

Hoda Anton-Culver ${ }^{3}$

\begin{abstract}
Background: The debate continues among medical professionals regarding the frequency, starting age, and stopping age for mammography screening. Some experts suggest tailoring recommendations based on individuals' personal breast cancer risk. Previous studies have not compared the impact of annual versus biennial mammography stratified by age group and risk category. The purpose of this study was to examine the relationship between mammography frequency and mortality by age group and risk category in the California Teachers Study.

Methods: Using data from study questionnaires from 93,438 women between the ages of 40 and 85 and linkages to the California Cancer Registry and other indices, overall and breast cancer-specific mortality by mammography frequency were estimated using multivariable Cox proportional hazards models, stratified by age group and risk category at baseline as determined by the Gail breast cancer risk model.

Results: During the follow-up period of 20 years, overall mortality risk was lower in women who had annual or biennial mammography compared to less frequent or no mammography in all age groups. Annual mammography was associated with lower overall mortality risk compared to biennial mammography among women age 50-85. This difference was especially apparent in women age 60-74, regardless of estimated Gail risk category at baseline. Breast cancer-specific mortality was lower among women who had annual mammography compared to biennial or less frequent mammography among women age 60-74, regardless of their baseline risk.
\end{abstract}

Conclusions: Our findings suggest that at least biennial mammography is beneficial to most women age 40-85 and that annual mammography is more beneficial than biennial mammography to most women age 50-85 in terms of overall mortality.

Keywords: Mammography, Mortality, Breast cancer risk, Cohort study

\section{Background}

Different professional and scientific organizations have different recommendations regarding the frequency, starting age, and stopping age for mammography screening in women. For example, currently the U.S. Preventive Services Task Force (USPSTF) recommends biennial mammography for most women age 50-74 [1], whereas

\footnotetext{
*Correspondence: hlpark@uci.edu

${ }^{2}$ Department of Epidemiology, School of Medicine, University

of California, Irvine, CA, USA

Full list of author information is available at the end of the article
}

the American Cancer Society (ACS) recommends annual mammography starting at age 45 , then biennial screening from age 55 for as long as the woman has a 10-year life-expectancy [2]. Meanwhile, the American College of Radiologists (ACR) [3], American College of Obstetrics and Gynecology (ACOG) [4] and National Comprehensive Cancer Network (NCCN) [5] also each have their own recommendations. Most mention that women should make individualized decisions to start screening earlier or to screen more frequently based on factors including their own personal risk. Recommendations for 
women age $\geq 75$ range from annual mammography (ACR [3] and NCCN [5]) to no recommendation (USPSTF [1]).

Systematic reviews of randomized clinical trials have generally reported that screening in women age $\geq 40$ is associated with decreased breast cancer mortality, with a larger magnitude of benefits observed in women age 50-69 compared to 40-49 [6-9]; however, other studies do not agree [10-13]. The concept of an individual's breast cancer risk playing a role in determining the mammography starting/stopping age or frequency has been a topic of interest, but there is no clear consensus on a recommendation. There is much variation among women and their referring providers' on their opinions and mammography practices [14-16].

While there have been studies examining the impact of getting mammography compared to not getting mammography on mortality in women with different risk statuses $[17,18]$, to our knowledge, previous analyses did not compare mortality risk in women who had annual versus biennial mammography stratified by age group and risk category. The purpose of this study was to examine screening mammography patterns among women in the California Teachers Study (CTS), a large, well-characterized prospective cohort, and to examine the relationships between mammography screening frequency, overall mortality, and breast cancer-specific mortality by age group and risk category during a follow-up period of 20 years.

\section{Material and methods Study population}

The California Teachers Study (CTS) is a prospective cohort of current or retired female public school teachers and administrators who were members of the California State Teachers Retirement System at the time of study inception in 1995-1996. As previously described [19], 133,477 women joined the CTS and completed a 16-page self-administered baseline questionnaire regarding their demographics, personal and family health history, lifestyle factors, and cancer screening history (including mammography) (https://www.calteachersstudy.org/pastquestionnaires).

We sequentially excluded from analyses women who at baseline were residing outside of California $(n=8851)$, had a history of breast cancer at baseline $(n=6216)$, were age $<40(n=20,321)$ or $>85$ years $(n=1833)$ at baseline, whose follow-up were $<6$ months $(n=407)$, those who had missing information regarding mammography use $(n=2407)$, and those whose baseline questionnaires were invalid or who withdrew from the study $(n=6) .93,438$ women comprised our analytic cohort (Supplemental Table).

\section{Outcomes}

Invasive breast cancer cases (designated by ICD-O-3 site codes 500-509 [excluding morphology codes 9590 9989]) were identified through annual linkage with the California Cancer Registry (CCR), a population-based, statewide cancer registration system that was legally mandated in California since 1988 and shown to be $>95 \%$ complete [20].

Deaths were identified via linkage with the State of California mortality files, the Social Security Administration Death Master File and the National Death Index. For overall mortality analyses, follow-up for this analysis was from baseline questionnaire completion until the earliest of the following: date of death due to any cause, move outside of California, or December 31st, 2015. For breast cancer-specific mortality, follow-up was from baseline until the earliest of the following: date of death due to invasive breast cancer, move outside of California, death due to other causes, or December 31st, 2015.

\section{Predictors}

The main independent variable was derived from questions in the baseline questionnaire which asked if the participant had ever had a mammogram (yes/no) and how long it had been since her last mammogram (less than 1 year, 1 to 2 years, $3+$ years). These questions served to estimate a woman's approximate mammography frequency $[21,22]$. For the purpose of this analysis, we combined women who never had a mammogram and women who reported their last mammogram was $3+$ years ago into one category ("never/less frequent"). Women who reported their last mammogram was $1-2$ years ago were categorized as "biennial," and women who reported their last mammogram was less than 1 year ago were categorized as "annual."

Age at baseline was categorized into four groups: $40-49,50-59,60-74$, and 75-85. Other covariates included race/ethnicity, alcohol consumption, body mass index, lifetime strenuous and moderate physical activity, smoking status, menopause status, comorbidities and hormone therapy use. Participants' comorbid conditions (history of diabetes, heart attack, stroke, or cancer) were collected from the baseline questionnaire and Office of Statewide Health Planning and Development (OSHPD) hospital discharge records from 1991 to 2015 [23]. In addition, we obtained self-reported number of first-degree relatives who had breast cancer. Estimated five-year breast cancer risk was calculated using the online NCI Breast Cancer Risk Assessment Tool (BCRAT) (http://www.cancer.gov/bcrisktool/), which includes age, race/ethnicity, history of breast biopsies, age at menarche, age when the woman gave birth to her 
first child, and first-degree family history of breast cancer, based on the Gail model [24], for each participant based on their baseline information. Participants in the highest quintile of Gail risk scores were categorized as high risk; the rest were low/average risk.

\section{Statistical analysis}

Chi-square tests were used in bivariate analyses to test for differences in demographic, behavioral characteristics and family history between mammography frequency groups. Overall and breast cancer-specific mortality rates were calculated for each age group. For each age group, time-to-event analysis was performed for the time from baseline to death or death due to breast cancer using Cox proportional hazards models. Participants who were alive at the end of follow-up were censored for overall mortality analysis. Participants who were alive or died from other causes were censored for breast cancer-specific mortality. Hazard ratios with $95 \%$ CI by mammography frequency were estimated adjusting for baseline age, race/ ethnicity, alcohol intake, BMI, lifetime physical activity, smoking status, menopause and hormone therapy status, history of heart attack, history of stroke, history of diabetes, or history of any cancer. Time-to-event analysis was also performed stratified by high or low/average Gail risk groups.

All $p$-values were two-tailed. Statistical significance was defined as $p \leq 0.05$. Data were analyzed using SAS and SAS/STAT Version 9.4 (SAS Institute, Cary, NC).

\section{Results}

Baseline characteristics of the study cohort are listed in Table 1 (as percentages of participants by mammography frequency in each age group) and in the Supplemental Table (as numbers and percentages of participants in each age group). Higher mammography frequency was observed in women age $50-74(69.0 \%$ in women age $50-59$ and $69.6 \%$ in women age $60-74$ were in the annual screening group) compared to younger (46.1\% in women age $40-49)$ and older (55.4\% in women age 75-85) women (Table 1). Differences in mammography frequency were observed according to all variables tested (Table 1 , all $p$-values $\leq 0.05$ ), most notably by race/ ethnicity, menopause/hormone therapy status, breast cancer family history, and Gail risk score. While differences were observed in all age groups, differences for some variables were most evident in women age 40-49. For example, among women age 40-49, 62.7\% of women with at least one first-degree family member with breast cancer had annual mammography compared to $44.0 \%$ of women with no family history. Similarly, $69.5 \%$ of women in the highest quintile of Gail 5-year risk had annual mammography compared to $39.8 \%$ in the lowest quintile (Table 1).

\section{Overall mortality}

During the 20-year follow-up period there were 20,148 deaths $(21.6 \%$ of the analytic cohort). Univariate and multivariable analyses showed that overall mortality risk was statistically significantly higher in women in the never/less frequent group compared to the biennial and annual groups among all age groups (Table 2, Never/Less frequent as referent). Further, among women in the 50 years and older age groups, overall mortality risk was statistically significantly lower in those who underwent annual mammography compared to biennial mammography $(\mathrm{HR}=0.90,95 \%$ CI $0.81,0.98, p<0.05$ in women age $50-59 ; \mathrm{HR}=0.87,95 \%$ CI 0.83 , $0.92, p<.001$ in women age $60-74$; and $\mathrm{HR}=0.91$, $95 \%$ CI $0.86,0.96, p<0.001$ in women age $75-85$ ) (Table 2, Biennial as referent).

Stratified analysis revealed that the increased overall mortality risk in women in the never/less frequent group compared to the biennial group was observed among women in both risk categories among all age groups but statistically significantly in the low/average Gail risk score category (HR $=1.43,95 \%$ CI 1.21, 1.70, $\mathrm{p}<0.001$ in women $40-49 ; \mathrm{HR}=1.19,95 \% \mathrm{CI} 1.02,1.40$, $\mathrm{p}<0.05$ in women $50-59$; and $\mathrm{HR}=1.14,95 \%$ CI 1.03 , $1.26, \mathrm{p}<0.05$ in women $60-74$, and $\mathrm{HR}=1.27,95 \% \mathrm{CI}$ $1.15,1.41$ in women age $75-85)$ as well as in women age $75-85(\mathrm{HR}=1.20,95 \% \mathrm{CI} 1.08,1.35, p<0.05)$ in the high risk category.

The decreased overall mortality risk in women age 50 years and older who had annual versus biennial mammograms remained statistically significant among women age 50-74 in the low/average risk category $(\mathrm{HR}=0.88,95 \%$ CI $0.79,0.97$, $p<0.01$ in women $50-59$; $\mathrm{HR}=0.87,95 \%$ CI 0.82 , $0.93, p<0.001$ in women $60-74)$ and in women $60-85$ in the high risk category $(\mathrm{HR}=0.88,95 \% \mathrm{CI}$ $0.82,0.95, p<0.001$ in women $60-74 ; \mathrm{HR}=0.88$, $95 \%$ CI $0.81,0.95, p<0.001$ in women $75-85$ ). Among women age 40-49, there was no difference in overall mortality risk between women who had annual versus biennial mammography in either risk category.

\section{Breast cancer-specific mortality}

Similar trends were observed for breast cancer-specific mortality, with significant mortality risk reduction among women age 60-74 in the annual group compared to the biennial and never/less frequent groups. 


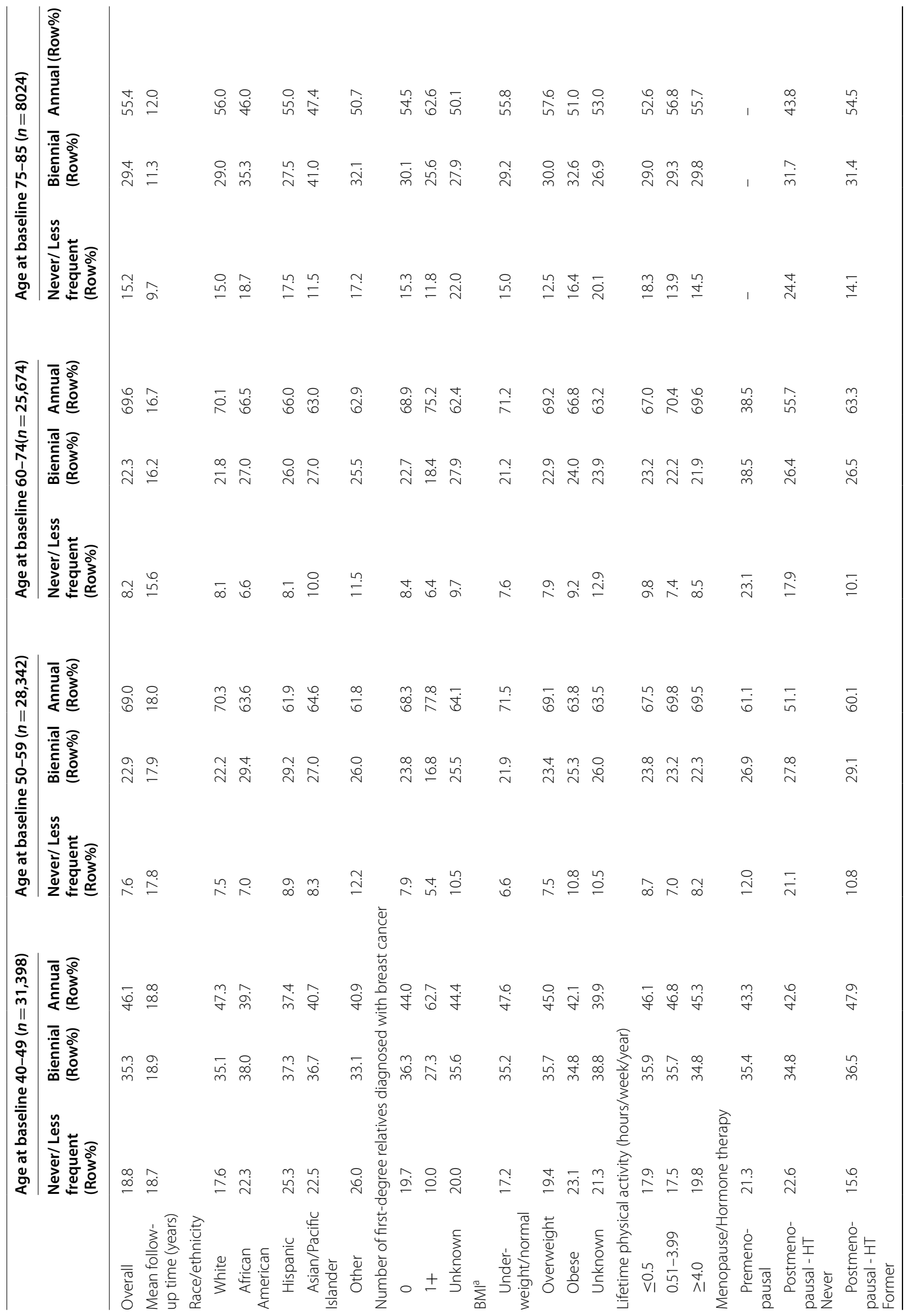




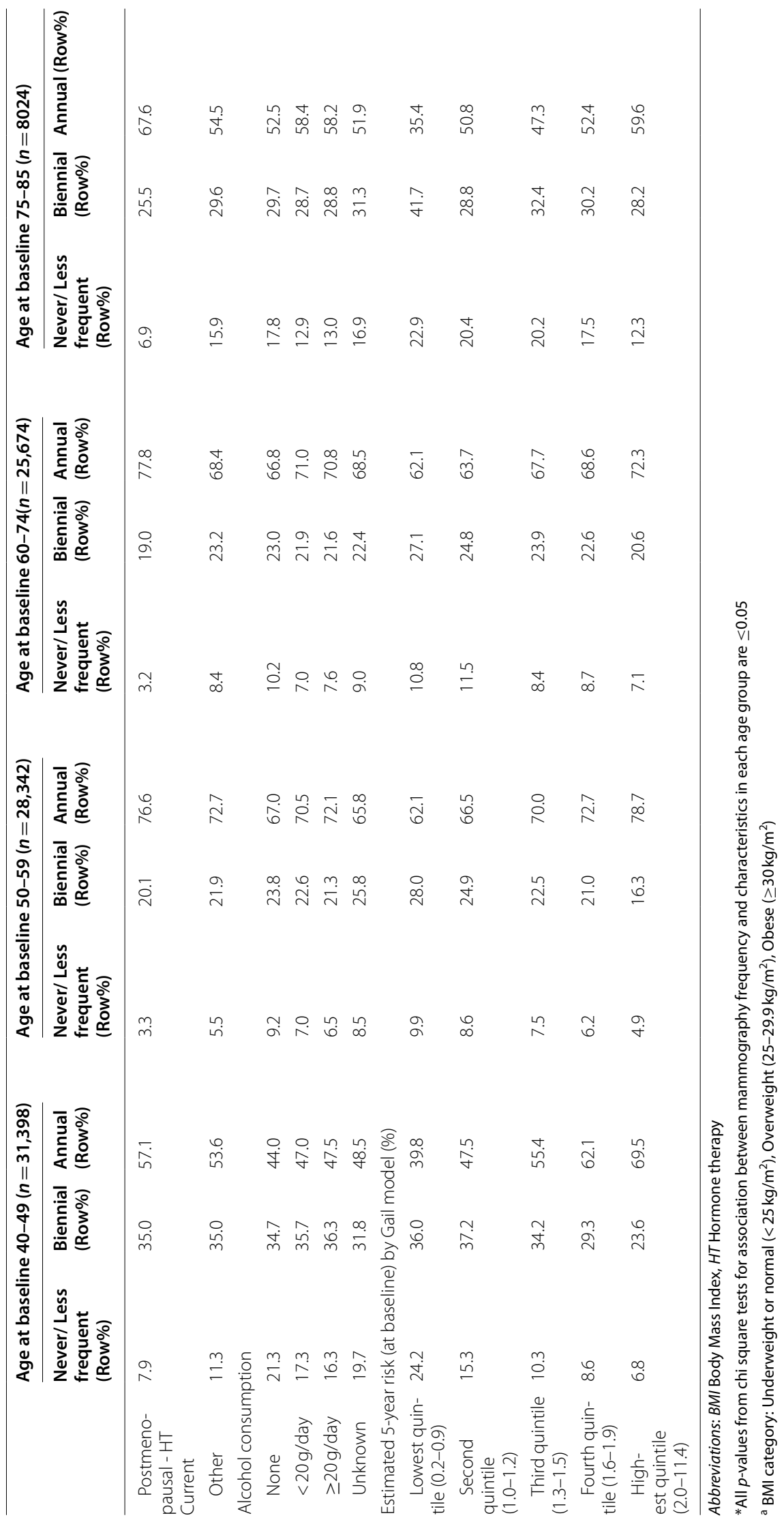


Table 2 Overall mortality rates by mammography frequency and age at baseline. Multivariable adjusted hazard ratios for overall mortality risk by mammography frequency, stratified by age group and breast cancer risk at baseline ${ }^{a}$

\begin{tabular}{|c|c|c|c|c|c|c|c|c|}
\hline \multirow[b]{3}{*}{$\begin{array}{l}\text { Univariate } \\
\text { Analysis }\end{array}$} & \multicolumn{8}{|c|}{ Age at baseline } \\
\hline & \multicolumn{2}{|c|}{$40-49(n=31,398)$} & \multicolumn{2}{|c|}{$50-59(n=28,342)$} & \multicolumn{2}{|c|}{$60-74(n=25,674)$} & \multicolumn{2}{|c|}{$75-85(n=8024)$} \\
\hline & Death (N) & $\begin{array}{l}\text { rate and } \\
95 \% \mathrm{Cl}^{\mathrm{b}}\end{array}$ & Death $(\mathrm{N})$ & $\begin{array}{l}\text { rate and } \\
95 \% \mathrm{Cl}^{\mathrm{b}}\end{array}$ & Death (N) & $\begin{array}{l}\text { rate and } \\
95 \% \mathrm{Cl}^{\mathrm{b}}\end{array}$ & Death (N) & $\begin{array}{l}\text { rate and } \\
95 \% \mathrm{Cl}^{\mathrm{b}}\end{array}$ \\
\hline \multicolumn{9}{|c|}{ Overall mortality } \\
\hline $\begin{array}{l}\text { Never/Less } \\
\text { frequent }\end{array}$ & 246 & $225(198,254)$ & 253 & $658(581,743)$ & 941 & $2877(2697,3065)$ & 1122 & $9513(8968,10,080)$ \\
\hline Biennial & 346 & $165(148,183)$ & 611 & $524(484,567)$ & 2324 & $2514(2413,2618)$ & 2050 & w \\
\hline Annual & 508 & $187(171,203)$ & 1629 & $460(438,482)$ & 6342 & $2127(2075,2180)$ & 3776 & $7069(6846,7297)$ \\
\hline $\begin{array}{l}\text { Multivari- } \\
\text { able analysis } \\
\text { (Never/Less } \\
\text { frequent as } \\
\text { referent) }\end{array}$ & \multicolumn{2}{|c|}{ HR $(95 \% \mathrm{Cl})$} & \multicolumn{2}{|c|}{ HR $(95 \% \mathrm{Cl})$} & \multicolumn{2}{|c|}{ HR (95\% Cl) } & \multicolumn{2}{|l|}{$\mathrm{HR}(95 \% \mathrm{Cl})$} \\
\hline $\begin{array}{l}\text { Never/Less } \\
\text { frequent }\end{array}$ & \multicolumn{2}{|l|}{ ref } & \multicolumn{2}{|l|}{ ref } & \multicolumn{2}{|l|}{ ref } & \multicolumn{2}{|l|}{ ref } \\
\hline Biennial & \multicolumn{2}{|c|}{$0.70(0.60,0.83)^{* * *}$} & \multicolumn{2}{|c|}{$0.83(0.72,0.97)^{*}$} & \multicolumn{2}{|c|}{$0.88(0.82,0.95)^{*}$} & \multicolumn{2}{|c|}{$0.80(0.75,0.86)^{* * *}$} \\
\hline Annual & \multicolumn{2}{|c|}{$0.76(0.65,0.89)^{* * *}$} & \multicolumn{2}{|c|}{$0.75(0.65,0.86)^{* * *}$} & \multicolumn{2}{|c|}{$0.77(0.72,0.83)^{* * *}$} & \multicolumn{2}{|c|}{$0.73(0.68,0.78)^{* * *}$} \\
\hline $\begin{array}{l}\text { Multivari- } \\
\text { able analysis } \\
\text { (Biennial } \\
\text { as referent } \\
\text { group) }\end{array}$ & \multicolumn{2}{|c|}{ HR $(95 \% \mathrm{Cl})$} & \multicolumn{2}{|c|}{$\operatorname{HR}(95 \% \mathrm{Cl})$} & \multicolumn{2}{|c|}{$\mathrm{HR}(95 \% \mathrm{Cl})$} & \multicolumn{2}{|c|}{$\mathrm{HR}(95 \% \mathrm{Cl})$} \\
\hline $\begin{array}{l}\text { Never/Less } \\
\text { frequent }\end{array}$ & \multicolumn{2}{|c|}{$1.42(1.20,1.68)^{* * *}$} & \multicolumn{2}{|c|}{$1.20(1.03,1.39)^{*}$} & \multicolumn{2}{|c|}{$1.14(1.05,1.23)^{*}$} & \multicolumn{2}{|c|}{$1.25(1.16,1.34)^{* * *}$} \\
\hline Biennial & \multicolumn{2}{|l|}{ ref } & \multicolumn{2}{|l|}{ ref } & ref & & ref & \\
\hline Annual & $1.09(0.95,1$ & & 0.90 (0.81, & & $0.87(0.83, c$ & $.92)^{* * *}$ & $0.91(0.86,0$ & 6)*** \\
\hline $\begin{array}{l}\text { Stratified } \\
\text { multivariable } \\
\text { analysisc }\end{array}$ & $\mathrm{HR}(95 \% \mathrm{Cl})$ & & HR $(95 \%$ C & & $\mathrm{HR}(95 \% \mathrm{Cl})$ & & $\mathrm{HR}(95 \% \mathrm{Cl})$ & \\
\hline Among low/ave & rage risk par & ants & & & & & & \\
\hline $\begin{array}{l}\text { Never/Less } \\
\text { frequent }\end{array}$ & $1.43(1.21,1$ & & $1.19(1.02$, & & $1.14(1.03,1$ & $26)^{*}$ & $1.27(1.15,1$ & $1)^{* * *}$ \\
\hline Biennial & ref & & ref & & ref & & ref & \\
\hline Annual & $1.09(0.94,1$ & & $0.88(0.79$, & & $0.87(0.82, c$ & $.93)^{* * *}$ & $0.94(0.87,1$ & \\
\hline Among high ris & participant & & & & & & & \\
\hline $\begin{array}{l}\text { Never/Less } \\
\text { frequent }\end{array}$ & $1.06(0.27,4$ & & 1.34 (0.85, & & $1.11(0.98,1$ & .26) & $1.20(1.08,1$ & \\
\hline Biennial & ref & & ref & & ref & & ref & \\
\hline Annual & $0.79(0.39,1$ & & 1.06 (0.80, & & $0.88(0.82,0$ & $95)^{* * *}$ & $0.88(0.81,0$ & $5)^{* * *}$ \\
\hline
\end{tabular}

Abbreviations: $H R$ Hazard ratio, $\mathrm{Cl}$ confidence interval, ref.: referent group

${ }^{a}$ Multivariable models adjusted for age at baseline, race/ethnicity, alcohol consumption, smoking, BMI, lifetime physical activity, menopause and hormone therapy status, comorbidity conditions including heart attack, stroke, diabetes and other cancer

${ }^{b}$ Overall mortality rate (number of deaths per 100,000 person-years)

${ }^{c}$ High risk participants were those in highest quintile of estimated baseline breast cancer risk as calculated by Gail model; rest of the participants were low/average risk

${ }^{*} p \leq 0.05,{ }^{* *} p \leq 0.01,{ }^{* * *} p \leq 0.001$ 
Table 3 Breast cancer-specific mortality rates by mammography frequency and age at baseline. Multivariable adjusted hazard ratios for breast cancer-specific mortality risk by mammography frequency, stratified by age group and estimated breast cancer risk at baseline $^{a}$

\begin{tabular}{|c|c|c|c|c|c|c|c|c|}
\hline \multirow[b]{3}{*}{$\begin{array}{l}\text { Univariate } \\
\text { analysis }\end{array}$} & \multicolumn{8}{|l|}{ Age at baseline } \\
\hline & \multicolumn{2}{|c|}{$40-49(n=31,398)$} & \multicolumn{2}{|c|}{$50-59(n=28,342)$} & \multicolumn{2}{|c|}{$60-74(n=25,674)$} & \multicolumn{2}{|c|}{$75-85(n=8024)$} \\
\hline & Death $(\mathrm{N})$ & $\begin{array}{l}\text { rate and } \\
95 \% \mathrm{Cl}^{\mathrm{b}}\end{array}$ & Death $(\mathrm{N})$ & $\begin{array}{l}\text { rate and } \\
95 \% \mathrm{Cl}^{\mathrm{b}}\end{array}$ & Death $(\mathrm{N})$ & $\begin{array}{l}\text { rate and } \\
95 \% \mathrm{Cl}^{\mathrm{b}}\end{array}$ & Death $(\mathrm{N})$ & $\begin{array}{l}\text { rate and } \\
95 \% \mathrm{Cl}^{\mathrm{b}}\end{array}$ \\
\hline \multicolumn{9}{|c|}{ Breast cancer mortality } \\
\hline $\begin{array}{l}\text { Never/Less } \\
\text { frequent }\end{array}$ & 30 & $27(19,39)$ & 17 & $44(27,69)$ & 34 & $104(73,144)$ & 11 & $93(49,162)$ \\
\hline Biennial & 42 & $20(15,27)$ & 41 & $35(26,47)$ & 73 & $79(62,99)$ & 17 & $64(38,100)$ \\
\hline Annual & 53 & $19(15,25)$ & 144 & $41(34,48)$ & 133 & $45(37,53)$ & 40 & $75(54,101)$ \\
\hline $\begin{array}{l}\text { Multivari- } \\
\text { able analysis } \\
\text { (Never/Less } \\
\text { frequent as } \\
\text { referent) }\end{array}$ & \multicolumn{2}{|l|}{ HR $(95 \% \mathrm{Cl})$} & \multicolumn{2}{|l|}{$\mathrm{HR}(95 \% \mathrm{Cl})$} & \multicolumn{2}{|l|}{ HR $(95 \% \mathrm{Cl})$} & \multicolumn{2}{|c|}{$\mathrm{HR}(95 \% \mathrm{Cl})$} \\
\hline $\begin{array}{l}\text { Never/Less } \\
\text { frequent }\end{array}$ & \multicolumn{2}{|l|}{ ref } & \multicolumn{2}{|l|}{ ref } & \multicolumn{2}{|l|}{ ref } & \multicolumn{2}{|l|}{ ref } \\
\hline Biennial & \multicolumn{2}{|l|}{$0.67(0.42,1.09)$} & \multicolumn{2}{|l|}{$0.86(0.48,1.52)$} & \multicolumn{2}{|c|}{$0.79(0.52,1.19)$} & \multicolumn{2}{|c|}{$0.67(0.31,1.44)$} \\
\hline Annual & \multicolumn{2}{|l|}{$0.65(0.41,1.04)$} & \multicolumn{2}{|l|}{$1.03(0.61,1.74)$} & \multicolumn{2}{|c|}{$0.44(0.30,0.66)^{* * *}$} & \multicolumn{2}{|c|}{$0.76(0.38,1.53)$} \\
\hline $\begin{array}{l}\text { Multivari- } \\
\text { able analysis } \\
\text { (Biennial } \\
\text { as referent } \\
\text { group) }\end{array}$ & \multicolumn{2}{|l|}{$\mathrm{HR}(95 \% \mathrm{Cl})$} & \multicolumn{2}{|l|}{$\mathrm{HR}(95 \% \mathrm{Cl})$} & \multicolumn{2}{|c|}{$\mathrm{HR}(95 \% \mathrm{Cl})$} & \multicolumn{2}{|c|}{$\mathrm{HR}(95 \% \mathrm{Cl})$} \\
\hline $\begin{array}{l}\text { Never/Less } \\
\text { frequent }\end{array}$ & \multicolumn{2}{|l|}{$1.48(0.92,2.40)$} & \multicolumn{2}{|l|}{$1.17(0.66,2.07)$} & \multicolumn{2}{|c|}{$1.27(0.84,1.93)$} & \multicolumn{2}{|c|}{$1.50(0.70,3.25)$} \\
\hline Biennial & \multicolumn{2}{|l|}{ ref } & \multicolumn{2}{|l|}{ ref } & ref & & ref & \\
\hline Annual & $0.97(0.65,1.45)$ & & $1.21(0.85,1.71)$ & & $0.56(0.42,0.7$ & & $1.15(0.65$ & \\
\hline $\begin{array}{l}\text { Stratified } \\
\text { multivariable } \\
\text { analysis }^{c}\end{array}$ & $\mathrm{HR}(95 \% \mathrm{Cl})$ & & HR $(95 \% \mathrm{Cl})$ & & HR $(95 \% \mathrm{Cl})$ & & $\operatorname{HR}(95 \%$ & \\
\hline Among low/av & rage risk particip & ants & & & & & & \\
\hline $\begin{array}{l}\text { Never/Less } \\
\text { frequent }\end{array}$ & $1.56(0.95,2.55)$ & & $1.24(0.65,2.34)$ & & $0.94(0.50,1.7$ & & $1.30(0.45$ & \\
\hline Biennial & ref & & ref & & ref & & ref & \\
\hline Annual & $0.93(0.61,1.44)$ & & $1.22(0.82,1.82)$ & & $0.63(0.42,0.9$ & & $1.19(0.52$ & \\
\hline Among high ris & k participants & & & & & & & \\
\hline $\begin{array}{l}\text { Never/Less } \\
\text { frequent }\end{array}$ & $0.62(0.06,6.38)$ & & $1.13(0.30,4.27)$ & & $1.63(0.92,2.8$ & & $1.74(0.56$ & \\
\hline Biennial & ref & & ref & & ref & & ref & \\
\hline Annual & $0.52(0.15,1.78)$ & & $0.98(0.46,2.09)$ & & $0.46(0.30,0.7$ & & $1.21(0.53$ & \\
\hline
\end{tabular}

Abbreviations: HR Hazard ratio, $\mathrm{Cl}$ confidence interval

a Multivariable models adjusted by age at baseline, race/ethnicity, alcohol consumption, smoking, BMI, lifetime physical activity, menopause and hormone therapy status, comorbidity conditions including heart attack, stroke, diabetes and cancer. Different referent groups were used in the overall model

${ }^{b}$ Breast cancer-specific mortality rate (number of breast cancer-specific deaths per 100,000 person-years)

c High risk participants were those in highest quintile of estimated baseline breast cancer risk as calculated by Gail model; rest of the participants were low/average risk

${ }^{*} p \leq 0.05,{ }^{* * *} p \leq 0.001$

Stratified analysis revealed that this association was consistent regardless of risk category $(\mathrm{HR}=0.63,95 \%$ CI $0.42,0.93, p<0.05$ in low/average risk women; $\mathrm{HR}=0.46$, 95\% CI 0.30, 0.71, $p<0.001$ in high risk women) (Table 3).

\section{Discussion}

With the disparate recommendations issued by organizations in the U.S. and elsewhere [25-29] and suggestions for personalized screening [30-32], we sought to examine the relationship between mammography 
screening frequency and mortality risk with consideration of age and estimated personal breast cancer risk category in the CTS, a large, well-characterized cohort of women with 20 years of follow-up. Since the biggest uncertainty and inconsistency between the recommendations, in addition to starting and stopping ages, pertains to biennial versus annual mammography, our analysis was focused on these two groups.

Despite the USPSTF recommendation during 19951996 for all women age $\geq 40$ to undergo annual mammography, only $60.3 \%$ of study participants in our analytic cohort of 93,438 women reported at baseline that they had their most recent mammogram in the past year. Consistent with other mammography studies, mammography frequency in our cohort was related to some factors classically associated with breast cancer risk, including race/ ethnicity, age, and family history [33-37]. That is, women at higher risk for breast cancer (older age, having a firstdegree relative with breast cancer) had more frequent mammography compared to women at lower risk, which is generally consistent with the concept of "risk-based screening." Our finding that higher rates of women who were taking hormone therapy had annual mammography compared to premenopausal women or postmenopausal women who were not taking hormone therapy may be reflective of older age, better compliance with following medical recommendations (since hormone therapy was recommended by the USPSTF and ACOG in 1995-1996 [38]), or better access to health care among these women.

Our results showing that biennial mammography was associated with decreased overall mortality risk compared to never/less frequent mammography among women in all age groups (age 40-85) are consistent with previous studies $[7,8]$ and may be related to the earlier detection of incident breast cancers. Subsequent analysis will be performed to examine the association for incidence among the 8102 incident breast cancer cases in our cohort. While the differences for women age 40-74 were only statistically significant in the low/average risk group, the trend was similar for women in the high risk groups, suggesting that the lack of statistical significance in these groups may be due to the low sample size of high risk women in the younger age groups. Taken together, our results suggest that biennial mammography is associated with decreased risk of overall mortality for women age 40-85 compared to never/less frequent mammography, regardless of Gail risk category. This result is consistent with the starting age currently recommended by the ACR [3] and NCCN [5], although they recommend annual mammography starting at age 40. ACS [2] and ACOG [4] guidelines state that providers should "offer" mammography to women starting at age 40 , while the USPSTF guidelines state that the decision to start mammography before age 50 should be an individual one [1].
Our results that, among women age 60-74, annual mammography was associated with decreased mortality risk compared to biennial mammography, regardless of risk category, are also consistent with current ACR [3] and NCCN [5] recommendations for annual screening for this age group. While our results also indicate that annual mammography was associated with decreased mortality risk among women age 50-59 with low/average risk, there was no association among women in this age group with high baseline risk, potentially due to the smaller sample size in this sub-group. Current recommendations from the ACS [2] and ACOG [4] for women age 50-74 call for biennial or annual mammography, while the USPSTF [1] recommends biennial mammography. While all of these recommendations allude to a shared decision-making process by patients and their health care providers, presumably based on their personal risk and preferences, our results suggest that Gail risk category at baseline would not differentiate between receiving benefit from annual compared to biennial mammography for women age 60-74. This does not, however, preclude the possibility that annual mammography may offer no additional benefit to some women according to risk stratification by other risk models or who meet other criteria.

The USPSTF stated that the current evidence is insufficient to assess the balance of benefits and harms of screening mammography in women aged 75 years or older [1]. However, our results showed that, among women age $75-85$, not only was never/less frequent mammography associated with increased overall mortality compared to biennial mammography, annual mammography was also associated with decreased overall mortality compared to biennial mammography. These results are in reasonable alignment with the ACS recommendation for screening as long as the woman has a life expectancy of 10 years [2], as well as the ACOG [4] and NCCN [5] recommendations, which call for consideration of the woman's current health status, and the ACR [3] recommendations, which do not mention a stopping age.

While we elected to use the modified Gail model (also known as the National Cancer Institute model) because its ease of use and validation in multiple large population databases in the U.S. [39], it would be prudent to do a similar analysis using risk scores calculated according to other validated risk models, including those which consider breast density and genetic profiling of high risk SNPs, since one's risk score is usually different according to different models [40-45].

Strengths of this study include the large, well-characterized prospective cohort, long follow-up time, high number of incident invasive breast cancer cases and deaths, and inclusion of major breast cancer risk 
factors including alcohol intake and physical activity in the multivariable analyses. The mortality outcomes were validated by linkage to the CCR and death indices as outlined in the Methods section. Limitations include that the participants were mostly nonHispanic white, educated, and had health insurance. $87.7 \%$ of women age $\geq 40$ in our cohort reported having had a mammogram within the past two years (of 1995-1996), compared to the national statistic of $60.9 \%$ in 1994 [46]. Thus, the results of this study may not be generalizable to women of different race/ethnicities, socioeconomic status, and access to health care. Also, there are likely other behavioral factors related to breast cancer risk and mortality that we did not account for, like healthful (risk reducing) or harmful (risk increasing) behaviors. Also, we assumed that participants' patterns of mammography screening did not change after their baseline questionnaire completed in 1995-1996. In 2006, the same mammography questions were asked in Questionnaire 5 (Q5), and there was an $82.8 \%$ agreement rate among participants who submitted both Q1 and Q5; thus, this assumption seems reasonable. And while the USPSTF guidelines for breast screening changed in 2009, instead recommending biennial mammograms starting at age 50 for most women, numerous studies have shown that screening practices did not change much after 2009 [14, 47-49]. Further, we performed a sensitivity analysis using this subset of Q1/ Q5 participants who had not been diagnosed with breast cancer before Q5, which showed estimates from multivariable models for overall mortality using mammography frequency reported in Q5 were similar to those using mammography frequency reported in Q1 but were not statistically significant due to the smaller number of events (and shorter follow-up time) in this subset (unpublished data).

Lastly, our study did not address potential harms of more frequent mammography, for example, false positive results, over-diagnosis, and decreased quality-adjusted life expectancy. However, these issues were not within the scope of this study, nor were other issues related to policy making. With that said, simulation modeling has shown that women who had higher breast cancer risk had lower rates of false positives and higher gains from screening than lower risk groups [50].

\section{Conclusions}

Our findings suggest that most women age 40-85 would benefit from biennial mammography compared to never/ less frequent mammography in terms of overall mortality risk. Further, most women age 50-85 would likely benefit from annual mammography compared to biennial mammography. Among women age 60-74, decreased mortality risk with annual mammography was seen among women in both high and low/average Gail risk categories. Further studies are needed to examine these associations stratified by risk categorizations based on different breast cancer risk models.

\section{Abbreviations \\ CTS: California Teachers Study; USPSTF: U.S. Preventive Services Task Force; ACR: American College of Radiologists; ACOG: American College of Obstetrics and Gynecology; NCCN: National Comprehensive Cancer Network; CCR: California Cancer Registry; OSPHD: Office of Statewide Health Planning and Development.}

\section{Supplementary Information}

The online version contains supplementary material available at https://doi. org/10.1186/s12885-021-09071-1.

Additional file 1: S1 Table. Baseline characteristics of 93,438 participants from California Teacher Study by age group.

\section{Acknowledgements}

The authors thank the California Teachers Study Steering Committee that is responsible for the formation and maintenance of the Study within which this research was conducted. A full list of California Teachers Study team members is available at https://www.calteachersstudy.org/team. Many thanks are also due to the California Teachers Study participants, who have given their time and commitment to the study since 1995. The data and information they provided have been an invaluable contribution to women's health and cancer research.

\section{Authors' contributions}

HLP, JC, AZ, and HAC contributed to the study design, data analysis, data interpretation, and manuscript preparation. VH contributed to data analysis and manuscript preparation. SSW contributed to data interpretation and manuscript preparation. All authors read and approved the final manuscript.

\section{Funding}

The California Teachers Study and the research reported in this publication were supported by the National Cancer Institute of the National Institutes of Health under award number U01-CA199277; P30-CA033572; P30-CA023100; UM1-CA164917; and R01-CA077398. The content is solely the responsibility of the authors and does not necessarily represent the official views of the National Cancer Institute or the National Institutes of Health. The collection of cancer incidence data used in the California Teachers Study was supported by the California Department of Public Health pursuant to California Health and Safety Code Section 103885; Centers for Disease Control and Prevention's National Program of Cancer Registries, under cooperative agreement 5NU58DP006344; the National Cancer Institute's Surveillance, Epidemiology and End Results Program under contract HHSN261201800032I awarded to the University of California, San Francisco, contract HHSN261201800015I awarded to the University of Southern California, and contract HHSN261201800009I awarded to the Public Health Institute. The opinions, findings, and conclusions expressed herein are those of the author(s) and do not necessarily reflect the official views of the State of California, Department of Public Health, the National Cancer Institute, the National Institutes of Health, the Centers for Disease Control and Prevention or their Contractors and Subcontractors, or the Regents of the University of California, or any of its programs.

Availability of data and materials

The datasets used and/or analyzed during the current study are available upon request via the "For Researchers" tab at https://www.calteachersstudy.org/. 


\section{Declarations}

\section{Ethics approval and consent to participate}

This study was carried out in compliance with the Helsinki Declaration and approved by the Institutional Review Board at the University of California Irvine (HS \#1998-453). All study participants provided written informed consent to participate in the study.

\section{Consent for publication}

Not applicable.

\section{Competing interests}

The authors declare that they have no competing interests.

\section{Author details}

'Department of Pathology and Laboratory Medicine, School of Medicine, University of California, Irvine, CA, USA. ${ }^{2}$ Department of Epidemiology, School of Medicine, University of California, Irvine, CA, USA. ${ }^{3}$ Department of Medicine, School of Medicine, University of California, Irvine, CA, USA. ${ }^{4}$ Department of Population Sciences, City of Hope, Duarte, CA, USA.

Received: 8 September 2021 Accepted: 25 November 2021 Published online: 18 December 2021

\section{References}

1. Siu AL, U.S. Preventive Services Task Force. Screening for Breast Cancer: U.S. Preventive Services Task Force Recommendation Statement. Ann. Intern. Med. 2016;164(4):279.

2. Oeffinger KC, et al. Breast Cancer screening for women at average risk: 2015 guideline update from the American Cancer Society. JAMA 2015;314(15):1599-614.

3. Monticciolo DL, et al. Breast Cancer screening for average-risk women: recommendations from the ACR Commission on breast imaging. J Am Coll Radiol. 2017;14(9):1137-43.

4. Committee on Practice Bulletins-Gynecology. Practice Bulletin Number 179: Breast Cancer Risk Assessment and Screening in Average-Risk Women. Obstet Gynecol. 2017:130:e1-e16.

5. National Comprehensive Cancer Network, "NCCN Clinical Practice Guidelines in Oncology: Breast Cancer Screening and Diagnosis. Version 1.2021.," 2021. [Online]. Available: https://www.nccn.org/professionals/ physician_gls/pdf/breast-screening.pdf. [Accessed: 10-Jun-2021].

6. Independent UK Panel on Breast Cancer Screening. The benefits and harms of breast cancer screening: an independent review. Lancet. 2012:380(9855):1778-86.

7. Canadian Task Force on Preventive Health Care, et al. Recommendations on screening for breast cancer in average-risk women aged 40-74 years. CMAJ. 2011;183(17):1991-2001.

8. Myers ER, et al. Benefits and harms of breast Cancer screening. JAMA. 2015;314(15):1615.

9. Canelo-Aybar C, et al. Benefits and harms of breast cancer mammography screening for women at average risk of breast cancer: a systematic review for the European Commission initiative on breast Cancer. J Med Screen. 2021:28(4):389-404.

10. Jørgensen KJ, Gøtzsche PC, Kalager M, Zahl P-H. Breast Cancer screening in Denmark: a cohort study of tumor size and Overdiagnosis. Ann Intern Med. 2017;166(5):313-23.

11. Autier P, Boniol M, Koechlin A, Pizot C, Boniol M. Effectiveness of and overdiagnosis from mammography screening in the Netherlands: population based study. BMJ. 2017;359:j5224.

12. Gøtzsche PC, Jørgensen KJ. Screening for breast cancer with mammography. Cochrane Database Syst. Rev. 2013;6:CD001877.

13. Miller AB, Wall C, Baines CJ, Sun P, To T, Narod SA. Twenty five year follow-up for breast cancer incidence and mortality of the Canadian National Breast Screening Study: randomised screening trial. BMJ. 2014;348:g366

14. Scheel JR, et al. Are physicians influenced by their own specialty Society's guidelines regarding mammography screening? An analysis of nationally representative data. Am J Roentgenol. 2016;207(5):959-64.
15. Anderson BL, Pearlman M, Griffin J, Schulkin J. Conflicting and changing breast Cancer screening recommendations: survey study of a National Sample of Ob-gyns after the release of the 2009 USPSTF guidelines. J Healthc Qual. 2013;35(4):25-35.

16. Allen SV, et al. Patient understanding of the revised USPSTF screening mammogram guidelines: need for development of patient decision aids. BMC Womens Health. 2012;12(1):36.

17. Duffy $\mathrm{S}$, et al. Evaluation of mammographic surveillance services in women aged $40-49$ years with a moderate family history of breast cancer: a single-arm cohort study. Heal. Technol Assess. 2013;17(11):vii-xiv, $1-95$.

18. Maurice A, et al. Screening younger women with a family history of breast cancer - does early detection improve outcome? Eur J Cancer. 2006;42(10):1385-90.

19. Bernstein $L$, et al. High breast cancer incidence rates among California teachers: results from the California teachers study (United States). Cancer Causes Control. 2002;13(7):625-35.

20. Parikh-Patel A, Allen M, Wright WE, California Teachers Study Steering Committee. Validation of self-reported cancers in the California Teachers Study. Am. J. Epidemiol. 2003:157(6):539-45.

21. Vernon SW, Briss PA, Tiro JA, Warnecke RB. Some methodologic lessons learned from cancer screening research. Cancer. 2004;101(S5):1131-45.

22. Blair E, Burton S. Cognitive processes used by survey respondents to answer behavioral frequency questions. J Consum Res. 1987;14(2):280.

23. California Office of Statewide Health Planning and Development (OSPHD). Patient discharge data file documentation: January-December 2012.

24. Gail MH, et al. Projecting individualized probabilities of developing breast cancer for white females who are being examined annually. J Natl Cancer Inst. 1989;81(24):1879-86.

25. Autier $\mathrm{P}$, Boniol M. Mammography screening: a major issue in medicine. Eur J Cancer. 2018;90:34-62.

26. Chen $\mathrm{TH}-\mathrm{H}$, et al. Clarifying the debate on population-based screening for breast cancer with mammography. Medicine (Baltimore). 2017:96(3):e5684.

27. Esserman LJ, WISDOM Study and Athena Investigators. The WISDOM Study: breaking the deadlock in the breast cancer screening debate. NPJ Breast Cancer. 2017;3(1):34

28. Kaniklidis C, N. S. B. C. No Surrender Breast Cancer Foundation. The mammography debate: the senior years. Curr. Oncol. 2016;23(3):e162-4.

29. Bleyer A. Screening mammography. Acad Radiol. 2015;22(8):949-60.

30. Schousboe JT, Kerlikowske K, Loh A, Cummings SR. Personalizing mammography by breast density and other risk factors for breast Cancer: analysis of health benefits and cost-effectiveness. Ann Intern Med. 2011;155(1):10.

31. Trentham-Dietz A, et al. Tailoring breast Cancer screening intervals by breast density and risk for women aged 50 years or older: collaborative modeling of screening outcomes. Ann Intern Med. 2016;165(10):700.

32. Shieh $Y$, et al. Breast Cancer Screening in the Precision Medicine Era: Risk-Based Screening in a Population-Based Trial. J. Natl. Cancer Inst. 2017:109(5):djw290.

33. Haber G, Ahmed NU, Pekovic V. Family history of Cancer and its association with breast Cancer risk perception and repeat mammography. Am J Public Health. 2012;102(12):2322-9.

34. Murabito JM, et al. Family breast cancer history and mammography: Framingham offspring study. Am J Epidemiol. 2001;154(10):916-23.

35. Tracy KA, et al. The impact of family history of breast cancer and cancer death on women's mammography practices and beliefs. Genet Med. 2008;10(8):621-5

36. Gross CP, Filardo G, Singh HS, Freedman AN, Farrell MH. The relation between projected breast Cancer risk, perceived Cancer risk, and mammography use. Results from the National Health Interview Survey. J Gen Intern Med. 2006;21(2):158-64.

37. Wells KJ, Roetzheim RG. Health disparities in receipt of screening mammography in Latinas: a critical review of recent literature. Cancer Control. 2007;14(4):369-79.

38. Nawaz H, Katz DL. American college of preventive medicine practice policy statement Perimenopausal and postmenopausal hormone replacement therapy. Am J Prev Med. 1999;17(3):250-4.

39. Gail MH. Choosing Breast Cancer Risk Models: Importance of Independent Validation. J Natl Cancer Instit. 2020;112(5):433-5. 
40. Brentnall AR, et al. Mammographic density adds accuracy to both the Tyrer-Cuzick and Gail breast cancer risk models in a prospective UK screening cohort. Breast Cancer Res. 2015;17(1):147.

41. Ziv E, Tice JA, Sprague B, Vachon CM, Cummings SR, Kerlikowske K. Using Breast Cancer Risk Associated Polymorphisms to Identify Women for Breast Cancer Chemoprevention. PLoS One. 2017;12(1):e0168601.

42. Brentnall AR, Cuzick J, Buist DSM, Bowles EJA. Long-term Accuracy of Breast Cancer Risk Assessment Combining Classic Risk Factors and Breast Density. JAMA Oncol. 2018;4(9):e180174.

43. Cuzick J, et al. Impact of a panel of 88 single nucleotide polymorphisms on the risk of breast Cancer in high-risk women: results from two randomized tamoxifen prevention trials. J Clin Oncol. 2017;35(7):743-50.

44. Park HL, et al. Clinical implementation of a breast cancer risk assessment program in a multiethnic patient population: Which risk model to use? Breast J. 2015;21(5):562-4.

45. Tice JA, Miglioretti DL, Li CS, Vachon CM, Gard CC, Kerlikowske K. Breast density and benign breast disease: risk assessment to identify women at high risk of breast Cancer. J Clin Oncol. 2015:33(28):3137-43.

46. National Center for Health Statistics (US). Health, United States, 2016: With Chartbook on Long-term Trends in Health. Hyattsville (MD): National Center for Health Statistics (US); Report No.: 2017-1232. 2017.

47. Pace LE, He Y, Keating NL. Trends in mammography screening rates after publication of the 2009 US preventive services task force recommendations. Cancer. 2013;119(14):2518-23.

48. Wang AT, et al. Impact of the 2009 US preventive services task force guidelines on screening mammography rates on women in their 40s. PLoS One. 2014;9(3):e91399.

49. Howard DH, Adams EK. Mammography rates after the 2009 US preventive services task force breast cancer screening recommendation. Prev Med (Baltim). 2012;55(5):485-7.

50. Mandelblatt JS, et al. Collaborative modeling of the benefits and harms associated with different U.S. breast Cancer screening strategies. Ann Intern Med. 2016;164(4):215-25.

\section{Publisher's Note}

Springer Nature remains neutral with regard to jurisdictional claims in published maps and institutional affiliations.

Ready to submit your research? Choose BMC and benefit from:

- fast, convenient online submission

- thorough peer review by experienced researchers in your field

- rapid publication on acceptance

- support for research data, including large and complex data types

- gold Open Access which fosters wider collaboration and increased citations

- maximum visibility for your research: over $100 \mathrm{M}$ website views per year

At BMC, research is always in progress.

Learn more biomedcentral.com/submissions 